\title{
A rapid review of digital health strategies and policies in response to COVID-19 pandemic.
}

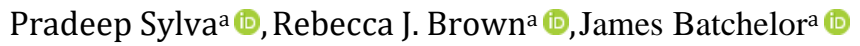

ABSTRACT

Introduction: COVID-19 pandemic has imposed unprecedented healthcare challenges, both globally and locally. The application of digital technologies offers great value for overcoming these challenges. However, the adoption itself has not been sufficient, appropriate, or uniform. In this regard, successful digital health strategies and policies adopted during this pandemic may form the basis to form exemplars for digital health adoption in similar situations. This study aims at reviewing the above-mentioned digital health strategies and policies with a view of creating value.

Methods: A rapid literature search was done through the Research4Life of Health InterNetwork Access to Research Initiative (HINARI). Search terms included word combinations to capture all publications related to the current pandemic and digital health strategies from the 1st of January to the 28th of May 2020. First, abstracts were examined for relevance. All works with significant content related to digital health strategies were included for full-text screening. Finally, an in-depth scrutiny of significant works was performed.

Results: Search results included 44 abstracts with six duplicates. After initial screening, 38 were selected for full-text screening. Only 26 significantly relevant studies were selected for the final analysis. Studies revealed a variety of digital health strategies adopted by countries and healthcare facilities during COVID -19. Telecare was the most conferred strategy globally (mentioned in 14 studies), where teleconsultations were key in remote service provision. Application of mHealth (two studies), electronic medical record (one study), clinical decision support systems (one study), and social media apps (four studies) have also created great value. Clinical applications included oncologic care, ophthalmic practice, geriatric care, dermatology, psychiatry, oral and maxillofacial surgery, otolaryngology, and electrophysiology. The above was in addition to general patient care, teaching, knowledge sharing, and research. Some have questioned the practicality of the above strategies, whereas the others have cited economic disparities, technology issues, information quality, legislation, and other contextual issues. Moreover, deficiencies in digital health policies at the global level were highlighted, emphasizing the need to strengthen global readiness for digital health adoption.

Conclusion: This study summarizes strategies used by countries and health facilities to utilize the full potential of digital health applications during pandemics. The above principles may form part of mainstream policies and strategies for delivering healthcare and international corporation in similar situations. The study further highlights the need for an immediate and inclusive global dialogue in this regard.

Keywords: Strategy, Policy, COVID-19, Digital Health, eHealth, mHealth, Telemedicine, Social-media

\section{INTRODUCTION}

The current COVID-19 pandemic has created many challenges in multiple sectors, both globally and locally(1). Many countries have taken drastic measures like unprecedented quarantine, social distancing, border closing, and even declaring "a state of emergency"(2). a Clinical Informatics Research Unit, Faculty of Medicine, University of Southampton, Southampton, UK

Correspondence to: Pradeep Sylva, Clinical Informatics Research Unit, Faculty of Medicine, University of Southampton, Southampton, UK

pradeepsylva@gmail.com ORCID ID: https://orcid.org/00000002-1133-3375

Article history:

Received 11 June 2020 Revised 29 June 2020 Accepted 30 June 2020 Published 31 October 2020

DOI:

http://doi.org/10.4038/sljb mi.v11i1.8097

(c) This is an open access article licensed under a Creative Commons Attribution-Share Alike 4.0 International License (CC BY-SA 4.0), which permits unrestricted use, distribution and reproduction in any medium, provided the original author and source are attributed and materials are shared under the same license.

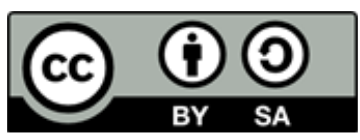


However, the resulting intermediate and long-term effects on the economies, owing to a marked decrease in global trade and closure of business, are yet to be fully absorbed. Conversely, the catastrophic effects on healthcare delivery and related pandemic management have created many immediate and crippling challenges. In addition to general healthcare, the affected response areas for pandemic management include early diagnosis, patient isolation, contact tracing, and symptomatic monitoring, monitoring of suspected and confirmed cases, and public health quarantine(3). Here, the potential of digital technologies, from telecare to mobile health apps and other disruptive technologies, could offer an unparalleled value in overcoming the pandemic associated challenges ${ }^{(4)}$.

However, adopting these digital health technologies by different countries and healthcare facilities has not been sufficient, appropriate, or uniform. It is observed that these efforts have created many challenges in the volatile, resource-hungry, and characteristically unique healthcare settings(5). Moreover, a certain degree of over-emphasis and over-reliance on the technological capabilities of digital health applications is imminent(6). Hence, the need to adopt clear, consistent, appropriate, and pragmatic digital health strategies to capture its full potential has become increasingly important.

Successful strategies and policies on digital health adoption by different countries and healthcare facilities during the current COVID-19 pandemic could guide the current approaches in digital health adoption. Lessons learned from both success stories and failures could guide alternating current strategies and be an impetus to formulate more robust future strategies. This study aims at reviewing global, country, and facility-level digital health strategies and policies adopted during this pandemic, with a view of creating valuable inputs to digital health planners and adopters.

\section{METHODS}

A rapid review method was followed to explore the digital health strategies and policies adopted by different countries and healthcare facilities during the COVID -19 pandemic. The study period was from the 1st of January to the 28th of May 2020. A bibliographical database search was done through Research4Life -HINARI of the World Health Organisation (WHO), using the search term ((Abstract:(covid-19)) OR (Abstract:("covid19")) OR (Abstract:("coronavirus")) OR (Abstract:("pandemic"))) AND ((Abstract:("digital AND health")) OR (Abstract:(ehealth)) OR (Abstract:(mhealth)) OR
(Abstract:(telemedicine)) OR (Abstract:(telehealth)) OR (Abstract:("health information"))) AND ((strategy) OR (policy)). This search term included keywords to capture all publications related to the current pandemic on digital health-related strategies and policies. The filters used were the English language and the above specified period of time.

All abstracts were examined for relevance at the initial screening. All articles with content related to digital health strategies and policies were selected. The articles which highlighted the deficiencies of the strategies or stressed the absolute absence of a strategy during digital health adoption were also included for full-text screening. All other works, including studies done on digital health applications, but not related to digital health policy and strategy, were excluded. The full-text screening was done after that, followed by in-depth scrutiny of the content.

\section{RESULTS}

The literature search resulted in 44 study abstracts with six duplicates. After the initial screening of abstracts for relevance, 38 were selected for full-text screening. The full-text screening revealed 26 significantly relevant works discussed in this study (Figure 1).

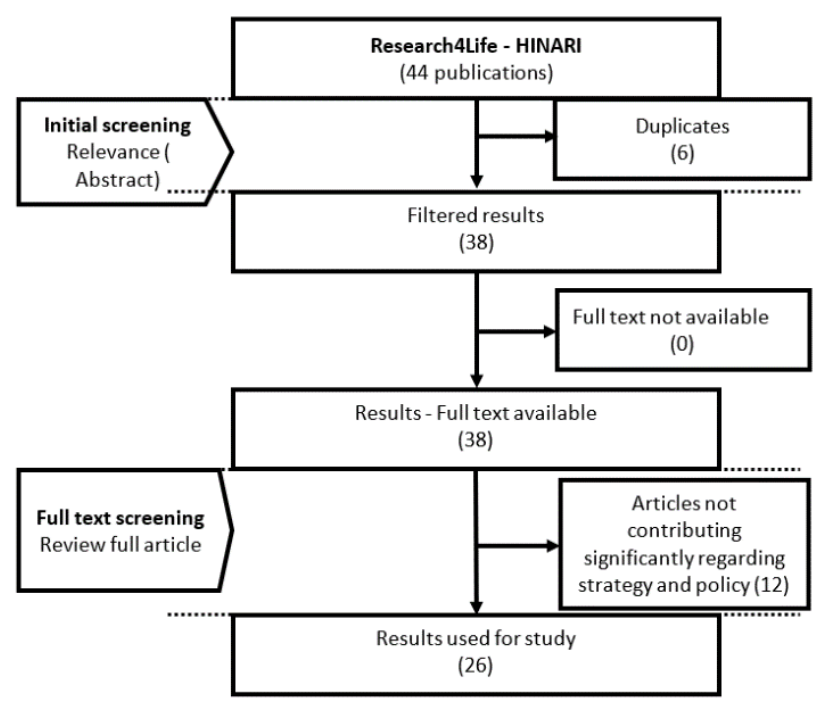

Figure 1: Rapid literature review results

The articles revealed a wide variety of digital health strategies and policies adopted by different countries and healthcare facilities during the COVID -19 pandemic. They were related to different digital health components such as Telehealth and Telemedicine (Telecare) (14 articles), mHealth (2 articles), Electronic Medical Record (EMR) (1 article), Clinical Decision Support Systems (DSS) 
( 1 article), social media applications and (4 articles) general email (Appendix: Table 1).

Clinical use of digital health was found to be described concerning telephonic consultations ( 4 articles), video consultations ( 4 articles), remote monitoring ( 2 articles), and web-based triage ( 2 articles). Further, digital health applications were used in clinical specialties such as oncologic care ( 4 articles), ophthalmic practice ( 2 articles), geriatric care (2 articles), dermatology (1 article), psychiatry (1 article), oral and maxillofacial surgery (1 article), otolaryngology (2 articles), electrophysiology (1 article) and COVID-19 (2 articles). This is in addition to in general patient care, teaching, knowledge sharing (2 articles), and research (1 article) (APPENDIX I).

Few articles described the implications of contextual factors in adopting digital health strategies. Further, there were clear indications of deficiencies in digital health strategies and policies at the global level.

\section{DISCUSSION}

Numerous digital health strategies and policies have been adopted during the current pandemic to harness the potential of digital health as an enabler for pandemic management. The adopted strategies have catered for many aspects, from supporting rapid information needs to change in conventional care delivery.

At present, challenges associated with social distancing, containment, isolation, and surge in capacity requirements of health facilities have become overwhelmingly high(2). Evidence suggests that Telehealth and Telemedicine adoption as supportive measures have been successful during past epidemics ${ }^{(3,7)}$. Similarly, this strategy was one of the more widely adopted digital health strategies by many countries during the present COVID-19 pandemic. These include technologically-assisted care delivery strategies, such as Telemedicine and web-based triage(2). A web-based COVID-19 screening process (a Tele-triage) is implemented in the United States of America (USA) to evaluate and classify the risk of COVID-19 infection and provide guidance on the next steps of action ${ }^{(8)}$. The United Kingdom and the USA have mainly used video consultations in a broader and scaled-up manner to reduce disease transmission risk in clinical settings ${ }^{(3)}$. This has also become useful in other countries under lockdown, where severe limitations on people's movement were imposed. Some studies conducted on the use of telephonic advice and other teleconsultations for ophthalmic practice have revealed a wider acceptance of such technologies $(9,10)$.
Another application with wider use is telepsychiatry(11). Under current lockdowns, the issue of potential threat to children and adolescents' mental health is expected to increase significantly ${ }^{(11)}$. Here, telepsychiatry has created a way of providing efficient and effective care. It has been observed that the COVID-19 related mortality among older populations is significantly high. Thus, phone calls, video telehealth ${ }^{(12)}$, and other means of telecommunication have enabled the provision of psychological support and close monitoring within the limitations of strict social distancing. This has considerably contributed to the prevention of anxiety and depression ${ }^{(13)}$ among the elderly population.

Teledermatology has been tested and resulted in excellent outcomes during the pandemic. Scaled up by algorithms and strict guidelines to prioritize the utilisation, dermatology consultations have been successfully used, specifically for inpatients in some facilities ${ }^{(14)}$. Chauhan et al. highlight another instance of remote monitoring using home or community-based pulse oximetry, combined with telemedicine services. This is useful in the early detection of patients who may be entering the rapid deterioration phase of COVID-19(15). Further, teleconsultations and online teaching methods have also been useful in oral and maxillofacial settings.

However, Maurrasse et al. claim a different perspective. Although otolaryngologists have been infected with COVID-19 at significantly higher $\operatorname{rates}^{(16)}$ in some countries and there are clear indications and encouragement for the use of teleconsultations in paediatric otolaryngology(5), some new concerns about protocols have emerged. Although the current crisis has removed many of the administrative, financial, and legal barriers to Telehealth, the role of regulation has dropped to minimal. Further, concerns are raised on the practicality of application, especially with inpatient paediatric clients. There is also ambiguity and concerns on case selection for teleconsultations for the time-sensitive pathologies of this specialty. Moreover, initial experiences of teleconsultations have had negative feedback from most care providers and patents alike. They were attributable to longer consultation times and technical issues(11) of connectivity, sign-in, and frequent virtual "no-shows"(5). Issues of privacy have been highlighted, especially in telepsychiatry, where the opportunity for a safe, confidential space at home can be questionable(11).

However, in general, telecare can effectively support efficient resource allocation and mobilization during a 
pandemic. Customized services can remotely identify patients who may require further attention and escalation of care. Further, gate-keeping and coordination mechanisms will ensure more appropriate use of provider offices, emergency departments, and hospitals(17).

This pandemic has created an immediate threat to most routine healthcare services, giving them less priority and attention. Most other healthcare services and elective procedures, including oncologic surgeries, have almost come to a definite halt(18), forming a critical concern in managing cancer patients. This is apprehended in addition to the estimated two-fold increase in the risk of COVID-19 infections in such patients(19). A study on the use of teleconsultations at a department of radiation oncology in a single health system in New York has revealed that almost all patient visits were changed to Telemedicine within two weeks.

There are certain barriers, such as the lack of regulatory frameworks and integration issues in the practice of Telehealth and Telemedicine. Therefore, the authorization, integration, and reimbursement of telemedicine services have lagged far behind, even in emergency and outbreak situations in many countries. Some countries like France have taken the initiative to actively support the use of Telemedicine coupled with rapid authorization and reimbursement(3). While in Italy, Telemedicine is not yet included as a basic level of care granted to all citizens within their National Health Service ${ }^{(3)}$. In this context, it is recommended that countries identify specific challenges in adopting Telemedicine with a broader global dialogue to overcome such challenges through collaborative efforts.

The use of Clinical Decision Support Systems (DSS) is no longer novel, but their application, specifically during a pandemic, could be considered an alternative strategy. Levin et al. have proposed a risk stratification plan provided by a DSS algorithm. This helps to delineate better those who require nebulized therapy in acute asthma management during the COVID-19 pandemic. The DSS protocols include strategies to allow flexibility in using Metered-Dose Inhalers (MDIs) rather than nebulizers in all but the most severe patients. This has helped to mitigate the risk of aerosolized nosocomial infections in patients and healthcare workers(20). Therefore, it can be argued that there may be more comprehensive applications of DSSs in pandemics or endemics, and further exploration of such is recommended.
The use of different mHealth apps and platforms strategically exploit the omnipresent nature of mobile devices. At the institutional level, Zamberg et al. describe the use of a dedicated mHealth platform as a means of an effective and time-saving communication channel to disseminate up-to-date and validated information about COVID-19. The platform has been used by all medical staff at the University Hospitals of Geneva(21) to an acceptable degree of success.

Another digital health strategy was promoting social media use by individuals, organizations, and governments to target a wider audience. There is increasing synchronization between ground level crisis response activities and their corresponding online presence as per Abd-Alrazaq et al. Therefore, a strategy of building national and international disease detection and surveillance systems through social media monitoring may result in an overall improvement(1) of disease surveillance mechanisms. The value of educating and empowering the public cannot be overemphasized in a pandemic. A study on dissemination channels for health education materials in Vietnam has revealed that mass media and peer-educator channels have a higher potential to be accessed to derive COVID-19 information when compared to organization or agency sources. It was further identified that most information was consumed via the internet, online newspapers, or social networks(22). This signifies the importance of tailoring digital health strategies to address the information needs of the current tech-savvy generation. Therefore, it is recommended to redesign training programs and communication activities in line with the above findings to ensure the effective dissemination of information in pandemics or epidemics.

Nevertheless, some of these digital health strategies have raised concerns and criticisms. One primary concern is the quality and credibility of online information. It can be suggested that a more proactive public health presence on the internet and social media by proper authorities may help curb the spread of fake news ${ }^{(1)}$. Further, it is recommended that governments develop policies and strategies to regulate health information on the internet instead of criticizing the information users(23). Another concern is the possible disparities in access to internetbased services, especially for marginalized communities. Furr-Holden et al. raise concerns over increasingly high volumes of crucial health-related information distributed through online services and apps. This may deprive the socially and economically disadvantaged populations of 
accessing such information. There could be information on the availability of testing facilities, care locations, ability to pay, transportation availability, and the status of health care providers ${ }^{(6)}$. Therefore, it is recommended to carefully assess the contextual factors, including access to the internet facilities of the intended audience, in devising the related digital health policies and strategies.

COVID-19 pandemic has also highlighted global challenges in cross-country collaborations. Efforts for rapidly sharing public health and scientific information, biological samples, and genetic sequence data among countries and global agencies like WHO, was found to be grossly inadequate. The deficiencies in global information sharing policies have contributed to this cause ${ }^{(24)}$. Rourke et al. emphasize the importance of more comprehensive, legally binding international policies for information sharing, beyond what is currently prescribed under the International Health Regulations (IHR). The current IHR lacks a broader definition of "public health information" and does not include genetic sequence data, nor does it include physical pathogen samples, both of which are crucial in controlling a pandemic. The importance of an immediate global dialogue in this regard is therefore highly recommended. It is also crucial to encourage and support research in the present context. COVID-19 research is found to be rapid, vast, and diverse. These may span from prediction of disease burden to global efforts on finding vaccinations. Digital health strategies should identify potential application areas for research and support health informaticians to achieve the best outcomes and benefits( ${ }^{(25)}$. The limitation of this study is that this was based on a rapid review method, and therefore a certain degree of bias is observed. The timing of this study relates to the plateau stage of the current wave of the pandemic, making it more challenging to identify the outcomes of some strategies and policies adopted. Further, a rapidly growing number of publications on this topic are seen, and the observations may not be conclusive. Studies with more comprehensive and systematic approaches are recommended to overcome these limitations towards the latter part of the timeline.

\section{CONCLUSIONS}

The digital health strategies and policies adopted during the current pandemic is diverse, with variable outcomes. This study summarises the strategies used by countries and health facilities to harness the full potential of digital health applications in the combat against the COVID-19 pandemic. There is clear potential in strategies related to Telehealth and Telemedicine, mHealth platforms and apps, Decision Support Systems, and the use of social media. Implications of contextual factors, including the existing digital health ecosystem and relevant legislation, or their deficiencies directly impact such policies and strategies. Further, the emphasis is drawn on the global readiness for digital health adoption and information sharing. A detailed analysis of outcomes in the postCOIVD-19 era could lead to a better understanding of the successes and failures of different strategies related to digital health.

The different facets of successful digital health adoptions and the strategies and policies thereto give a clear indication of a possible paradigm shift in healthcare provision in the COVID era - in the "new norm". Therefore, it is recommended to adopt clear, consistent, appropriate, and pragmatic digital health strategies to suit institutional, country and global levels, and future requirements. These strategies should be formulated, giving due consideration to possible implications of the existing digital health landscape, digital and healthcare infrastructure, human resource capacity, funding, and other existing policies, strategies, guidelines, regulations, and legislation. Further, the above may form part of the mainstream policies, strategies, and international regulations to deliver healthcare. Thus, there is an immediate need for an inclusive global dialogue in this regard.

\section{REFERENCES}

1. Abd-Alrazaq A, Alhuwail D, Househ M, Hamdi M, Shah Z. Top Concerns of Tweeters During the COVID-19 Pandemic: Infoveillance Study. Journal of medical Internet research. 2020;22(4):e19016.

2. Stawicki S, Jeanmonod R, Miller A, Paladino L, Gaieski D, Yaffee A, et al. The 2019-2020 novel coronavirus (severe acute respiratory syndrome coronavirus 2) pandemic: A joint american college of academic international medicine-world academic council of emergency medicine multidisciplinary COVID-19 working group consensus paper. Journal of Global Infectious Diseases. 2020;12(2):47-93.

3. Ohannessian R, Duong TA, Odone A. Global Telemedicine Implementation and Integration Within Health Systems to Fight the COVID-19 
Pandemic: A Call to Action. JMIR public health and surveillance. 2020;6(2):e18810.

4. Pérez Sust P, Solans O, Fajardo JC, Medina Peralta M, Rodenas $\mathrm{P}$, Gabaldà J, et al. Turning the Crisis Into an Opportunity: Digital Health Strategies Deployed During the COVID-19 Outbreak. JMIR public health and surveillance. 2020;6(2):e19106.

5. Maurrasse SE, Rastatter JC, Hoff SR, Billings KR, Valika TS. Telemedicine During the COVID-19 Pandemic: A Pediatric Otolaryngology Perspective. Otolaryngology-Head and Neck Surgery. 2020;(Journal Article):19459982093182.

6. Furr-Holden D, Carter-Pokras O, Kimmel M, Mouton C. Access to Care During a Global Health Crisis. Health Equity. 2020;4(1):15-157.

7. Chersich MF, Gray G, Fairlie L, Eichbaum Q, Mayhew S, Allwood B, et al. COVID-19 in Africa: care and protection for frontline healthcare workers. Globalization and health. 2020;16(1):46-6.

8. Schwamm LH, Erskine A, Licurse A. A digital embrace to blunt the curve of COVID19 pandemic. NPJ digital medicine. 2020;3(Journal Article):64.

9. Nair A, Gandhi R, Natarajan S. Effect of COVID-19 related lockdown on ophthalmic practice and patient care in India: Results of a survey. Indian Journal of Ophthalmology. 2020;68(5):725-30.

10. Williams AM, Kalra G, Commiskey PW, Bowers EMR, Rudolph BR, Pitcher MD, et al. Ophthalmology Practice During the Coronavirus Disease 2019 Pandemic: The University of Pittsburgh Experience in Promoting Clinic Safety and Embracing Video Visits. Ophthalmology and therapy. 2020;(Journal Article):1.

11. Fegert JM, Vitiello B, Plener PL, Clemens V. Challenges and burden of the Coronavirus 2019 (COVID-19) pandemic for child and adolescent mental health: a narrative review to highlight clinical and research needs in the acute phase and the long return to normality. Child and Adolescent Psychiatry and Mental Health. 2020;14(1):1-11.

12. Hoffman GJ, Webster NJ, Bynum JPW. A Framework for Aging-Friendly Services and Supports in the Age of COVID-19. Journal of aging \& social policy. 2020;(Journal Article):1-10.
13. Nguyen NP, Vinh-Hung V, Baumert B, Zamagni A, Arenas M, Motta M, et al. Older Cancer Patients during the COVID-19 Epidemic: Practice Proposal of the International Geriatric Radiotherapy Group. Cancers. 2020;12(5):1287.

14. Rismiller $\mathrm{K}$, Cartron AM, Trinidad JCL. Inpatient teledermatology during the COVID-19 pandemic. The Journal of dermatological treatment. 2020;(Journal Article):1-3.

15. Chauhan V, Galwankar S, Yellapu V, Perez-Figueroa I, Stawicki S. State of the globe: The trials and tribulations of the COVID-19 pandemic: Separated but together, telemedicine revolution, frontline struggle against 'Silent Hypoxia,' the relentless search for novel therapeutics and vaccines, and the daunting prospect of 'COVIFLU'. Journal of Global Infectious Diseases. 2020;12(2):39-43.

16. Cheng X, Liu J, Li N, Nisenbaum E, Sun Q, Chen B, et al. Otolaryngology Providers Must Be Alert for Patients with Mild and Asymptomatic COVID-19. Otolaryngology--head and neck surgery: official journal of American Academy of OtolaryngologyHead and Neck Surgery. 2020;(Journal Article):194599820920649.

17. Chauhan V, Galwankar S, Arquilla B, Garg M, Somma S, El-Menyar A, et al. Novel coronavirus (COVID-19): Leveraging telemedicine to optimize care while minimizing exposures and viral transmission. Journal of Emergencies, Trauma, and Shock. 2020;13(1):20-4.

18. Buckstein M, Skubish S, Smith K, Braccia I, Green S, Rosenzweig K. Experiencing the Surge: Report from a Large New York Radiation Oncology Department During the COVID-19 Pandemic. Advances in radiation oncology [Internet]. 2020;(Journal Article). Available from: https://pubmed.ncbi.nlm.nih.gov/32377596/

19. Al-Shamsi HO, Alhazzani W, Alhuraiji A, Coomes EA, Chemaly RF, Almuhanna $M$, et al. A Practical Approach to the Management of Cancer Patients During the Novel Coronavirus Disease 2019 (COVID-19) Pandemic: An International Collaborative Group. The oncologist [Internet]. 2020;(Journal Article). Available from: https://pubmed.ncbi.nlm.nih.gov/32243668/ 
20. Levin M, Morais-Almeida M, Ansotegui IJ, Bernstein J, Chang Y-S, Chikhladze $M$, et al. Acute asthma management during SARS-CoV2-pandemic 2020. The World Allergy Organization journal. 2020;13(5):100125.

21. Zamberg I, Manzano S, Posfay-Barbe K, Windisch O, Agoritsas T, Schiffer E. A Mobile Health Platform to Disseminate Validated Institutional Measurements During the COVID-19 Outbreak: Utilization-Focused Evaluation Study. JMIR public health and surveillance. 2020;6(2):e18668.

22. Tran BX, Dang AK, Thai PK, Le HT, Le XTT, Do TTT, et al. Coverage of Health Information by Different Sources in Communities: Implication for COVID-19 Epidemic Response. International Journal of Environmental Research and Public Health. 2020;17(10):3577.
23. Cuan-Baltazar JY, Muñoz-Perez MJ, Robledo-Vega C, Pérez-Zepeda MF, Soto-Vega E. Misinformation of COVID-19 on the Internet: Infodemiology Study. JMIR public health and surveillance. 2020;6(2):e18444.

24. Rourke M, Eccleston-Turner M, Phelan A, Gostin L. Policy opportunities to enhance sharing for pandemic research. Science (New York, NY). 2020;368(6492):716-8.

25. Moore JH, Barnett I, Boland MR, Chen Y, Demiris G, Gonzalez-Hernandez G, et al. Ideas for how informaticians can get involved with COVID-19 research. BioData Mining. 2020;13(1):1-16.

\section{APPENDIX I}

\begin{tabular}{|c|c|c|c|c|}
\hline & Application area & $\begin{array}{l}\text { Number } \\
\text { of } \\
\text { relevant } \\
\text { studies }\end{array}$ & $\begin{array}{l}\text { Region or } \\
\text { Countries }\end{array}$ & DOI \\
\hline \multirow{22}{*}{$\begin{array}{l}\text { Digital Health } \\
\text { Components }\end{array}$} & \multirow{14}{*}{$\begin{array}{l}\text { Telecare, Telehealth } \\
\text { and Telemedicine, }\end{array}$} & \multirow[t]{14}{*}{14} & USA & $10.1136 /$ tsaco-2020-000481 \\
\hline & & & USA & $10.1038 / \mathrm{s} 41746-020-0279-6$ \\
\hline & & & USA & 10.1016/j.adro.2020.04.014 \\
\hline & & & USA/UK & $10.2196 / 18810$ \\
\hline & & & $\begin{array}{l}\text { Unspecified/ } \\
\text { Multiple }\end{array}$ & 10.1634/theoncologist.2020-0213 \\
\hline & & & USA & 10.4103/jgid.jgid_86_20 \\
\hline & & & Africa & $10.1186 / \mathrm{s} 12992-020-00574-3$ \\
\hline & & & USA & 10.1161/CIRCULATIONAHA.120.047063 \\
\hline & & & Africa & $10.1186 / \mathrm{s} 12992-020-00574-3$ \\
\hline & & & USA & $10.1007 / \mathrm{s} 40123-020-00255-9$ \\
\hline & & & $\begin{array}{l}\text { Unspecified/ } \\
\text { Multiple }\end{array}$ & Unspecified/ Multiple \\
\hline & & & $\begin{array}{l}\text { Unspecified/ } \\
\text { Multiple }\end{array}$ & $10.1177 / 0194599820931827$ \\
\hline & & & USA & $10.1080 / 09546634.2020 .1762843$ \\
\hline & & & $\begin{array}{l}\text { Unspecified/ } \\
\text { Multiple }\end{array}$ & 10.4103/JETS.JETS_32_20 \\
\hline & \multirow[t]{3}{*}{ mHealth } & \multirow[t]{3}{*}{2} & Spain & $10.2196 / 19106$ \\
\hline & & & Switzerland & $10.2196 / 18668$ \\
\hline & & & USA & 10.1161/CIRCULATIONAHA.120.047063 \\
\hline & EMR & 1 & Spain & $10.2196 / 19106$ \\
\hline & $\begin{array}{l}\text { Clinical decision } \\
\text { support systems } \\
\text { (DSS) }\end{array}$ & 1 & $\begin{array}{l}\text { Unspecified/ } \\
\text { Multiple }\end{array}$ & 10.1016/j.waojou.2020.100125 \\
\hline & \multirow[t]{3}{*}{$\begin{array}{l}\text { Social media and } \\
\text { online sources }\end{array}$} & \multirow[t]{3}{*}{4} & $\begin{array}{l}\text { Unspecified/ } \\
\text { Multiple }\end{array}$ & $10.2196 / 19016$ \\
\hline & & & USA & 10.1089/heq.2020.29001.rtl2 \\
\hline & & & USA & $10.2196 / 18444$ \\
\hline
\end{tabular}




\begin{tabular}{|c|c|c|c|c|}
\hline & Application area & $\begin{array}{l}\text { Number } \\
\text { of } \\
\text { relevant } \\
\text { studies }\end{array}$ & $\begin{array}{l}\text { Region or } \\
\text { Countries }\end{array}$ & DOI \\
\hline & & & Vietnam & 10.3390/ijerph17103577 \\
\hline \multirow[t]{12}{*}{ Clinical Use } & \multirow{4}{*}{$\begin{array}{l}\text { Telephonic } \\
\text { consultations }\end{array}$} & \multirow[t]{4}{*}{4} & India & 10.4103/ijo.IJO_797_20 \\
\hline & & & USA & $10.1038 / \mathrm{s} 41746-020-0279-6$ \\
\hline & & & Africa & $10.1186 / s 12992-020-00574-3$ \\
\hline & & & $\begin{array}{l}\text { Unspecified/ } \\
\text { Multiple }\end{array}$ & $10.1080 / 08959420.2020 .1771239$ \\
\hline & \multirow[t]{4}{*}{ Video consultations } & \multirow[t]{4}{*}{4} & USA & $10.1038 / \mathrm{s} 41746-020-0279-6$ \\
\hline & & & USA & 10.1161/CIRCULATIONAHA.120.047063 \\
\hline & & & $\begin{array}{l}\text { Unspecified/ } \\
\text { Multiple }\end{array}$ & 10.1161/CIRCULATIONAHA.120.047063 \\
\hline & & & USA & $10.1007 / \mathrm{s} 40123-020-00255-9$ \\
\hline & \multirow[t]{2}{*}{ Remote monitoring } & \multirow[t]{2}{*}{2} & $\begin{array}{l}\text { Unspecified/ } \\
\text { Multiple }\end{array}$ & $10.3390 /$ cancers12051287 \\
\hline & & & $\begin{array}{l}\text { Unspecified/ } \\
\text { Multiple }\end{array}$ & $10.1080 / 08959420.2020 .1771239$ \\
\hline & \multirow{2}{*}{ Web-based triage } & \multirow[t]{2}{*}{2} & USA & 10.4103/jgid.jgid_86_20 \\
\hline & & & USA & $10.1038 / \mathrm{s} 41746-020-0279-6$ \\
\hline \multirow{22}{*}{$\begin{array}{l}\text { Clinical } \\
\text { specialty or } \\
\text { area of } \\
\text { practice }\end{array}$} & \multirow[t]{4}{*}{ Oncologic care } & \multirow[t]{4}{*}{4} & USA & 10.1016/j.adro.2020.04.014 \\
\hline & & & $\begin{array}{l}\text { Unspecified/ } \\
\text { Multiple }\end{array}$ & $10.1634 /$ theoncologist.2020-0213 \\
\hline & & & $\begin{array}{l}\text { Unspecified/ } \\
\text { Multiple }\end{array}$ & 10.3390/cancers12051287 \\
\hline & & & $\begin{array}{l}\text { Unspecified/ } \\
\text { Multiple }\end{array}$ & $10.1093 /$ jscr/rjaa157 \\
\hline & \multirow[t]{2}{*}{ Ophthalmic practice } & \multirow[t]{2}{*}{2} & India & 10.4103/ijo.IJO_797_20 \\
\hline & & & USA & $10.1007 / \mathrm{s} 40123-020-00255-9$ \\
\hline & \multirow[t]{2}{*}{ Geriatric care } & \multirow[t]{2}{*}{2} & $\begin{array}{l}\text { Unspecified/ } \\
\text { Multiple }\end{array}$ & $10.3390 /$ cancers12051287 \\
\hline & & & $\begin{array}{l}\text { Unspecified/ } \\
\text { Multiple }\end{array}$ & $10.1080 / 08959420.2020 .1771239$ \\
\hline & \multirow[t]{2}{*}{ COVID-19 } & \multirow[t]{2}{*}{2} & USA & $10.1038 / \mathrm{s} 41746-020-0279-6$ \\
\hline & & & $\begin{array}{l}\text { Unspecified/ } \\
\text { Multiple }\end{array}$ & 10.4103/jgid.jgid_96_20 \\
\hline & Dermatology, & 1 & USA & $10.1080 / 09546634.2020 .1762843$ \\
\hline & \multirow[t]{4}{*}{ Otolaryngology } & \multirow[t]{4}{*}{2} & USA & $10.1177 / 0194599820929613$ \\
\hline & & & $\begin{array}{l}\text { Unspecified/ } \\
\text { Multiple }\end{array}$ & $10.1177 / 0194599820920649$ \\
\hline & & & $\begin{array}{l}\text { Unspecified/ } \\
\text { Multiple }\end{array}$ & $10.1177 / 0194599820931827$ \\
\hline & & & $\begin{array}{l}\text { Unspecified/ } \\
\text { Multiple }\end{array}$ & $10.1177 / 0194599820931827$ \\
\hline & Psychiatry & 1 & Europe & $10.1186 / \mathrm{s} 13034-020-00329-3$ \\
\hline & $\begin{array}{l}\text { Oral and } \\
\text { maxillofacial surgery, }\end{array}$ & 1 & $\begin{array}{l}\text { Unspecified/ } \\
\text { Multiple }\end{array}$ & 10.1016/j.joms.2020.05.027 \\
\hline & Electrophysiology & 1 & USA & 10.1161/CIRCULATIONAHA.120.047063 \\
\hline & General patient care & & $\begin{array}{l}\text { Unspecified/ } \\
\text { Multiple }\end{array}$ & 10.4103/JETS.JETS_32_20 \\
\hline & \multirow{2}{*}{$\begin{array}{l}\text { Teaching and } \\
\text { Knowledge sharing }\end{array}$} & \multirow[t]{2}{*}{2} & Vietnam & 10.3390/ijerph17103577 \\
\hline & & & $\begin{array}{l}\text { Unspecified/ } \\
\text { Multiple }\end{array}$ & 10.1016/j.joms.2020.05.027 \\
\hline & Research & 1 & $\begin{array}{l}\text { Unspecified/ } \\
\text { Multiple }\end{array}$ & 10.1186/s13040-020-00213-y \\
\hline
\end{tabular}

